\title{
Solvent Extraction of Iron(II) and Iron(III) as Anionic Thiocyanate Complexes with Tetrabutylammonium Ions into Chloroform
}

\author{
Akinobu Nasu, Hitoshi Takagi, Yasunobu OhmiYa and Tatsuya SeKine \\ Department of Chemistry, Science University of Tokyo, Kagurazaka, Shinjuku, Tokyo 162-8601
}

Keywords Solvent extraction, iron(II), iron(III), thiocyanate complex, tetrabutylammonium ion

Both iron(II) and (III) form complexes in aqueous thiocyanate solutions ${ }^{1,2}$, and solvent extraction of these metal ions from the solutions is possible with different types of extractants. ${ }^{3}$ The solvent extraction of iron(III) has been studied with neutral extractants, such as ethers, ketones, alcohols and tributylphosphate, and also with cationic extractants, such as quaternary ammonium ions. ${ }^{3-8}$ However, the solvent extraction of iron(II) from thiocyanate solutions has not been studied very much. ${ }^{3}$

In the present work, the solvent extraction of iron(II) and (III) as anionic thiocyanate complexes with tetrabutylammonium ions into chloroform was studied and the equilibria among the chemical species were estimated by a statistical analysis of the data. The difference in the formation and extraction behaviors of the thiocyanate complexes in these oxidation states was considered by comparing the stability and extractability of the complexes in aqueous solutions.

\section{Experimental}

All of the reagents were of analytical grade. Sodium nitrate and sodium thiocyanate were recrystallized three times from water. Chloroform was washed several times with water before use.

All of the solvent-extraction procedures were carried out in a thermostated room at $298 \mathrm{~K}$. A stock solution of sodium thiocyanate was prepared by dissolving sodium thiocyanate crystals in water, and the concentration was determined by titration with a standard silver(I) nitrate solution. A stock solution of iron(III) was prepared by dissolving a weighed amount of ammonium iron(II) sulfate in nitric acid, and was left standing for more than $24 \mathrm{~h}$. The iron concentration in the solution was determined by EDTA titration. Stoppered glass tubes (capacity $20 \mathrm{~cm}^{3}$ ) were used for the solventextraction experiments. The vessels were covered by aluminum foil in order to avoid any effect of light. An aqueous solution was prepared by mixing $1 \mathrm{~mol} \mathrm{dm}^{-3}$ sodium thiocyanate solution and $1 \mathrm{~mol} \mathrm{dm}^{-3}$ sodium nitrate solution. To this aqueous solution, a small amount of nitric acid was added in order to adjust the initial hydrogen-ion concentration at $1.00 \times 10^{-1} \mathrm{~mol}$ $\mathrm{dm}^{-3}$, and an amount of aqueous solution containing tetrabutylammonium nitrate, $\mathrm{tba}^{+} \mathrm{NO}_{3}{ }^{-}$, was added. The solution was placed in a glass tube and a portion of chloroform was added. The two phases were agitated for about $5 \mathrm{~min}$, and then a portion of the iron(III) solution was added. The initial iron concentration in the aqueous phase was $2 \times 10^{-5} \mathrm{~mol} \mathrm{dm}^{-3}$ and the volume of each phase was $5 \mathrm{~cm}^{3}$. The two phases were agitated for about $30 \mathrm{~s}$ and centrifuged off. The extracted iron in the organic phase was stripped by $1 \mathrm{~mol} \mathrm{dm}^{-3}$ nitric acid. The iron content in this aqueous solution and that in the equilibrated aqueous phase was determined by atomic-absorption spectrometry.

Solvent-extraction experiments of iron(II) were carried out in a similar manner, except that an ascorbic acid solution was added to the aqueous phase just before starting the experiments. The initial concentration of this reductant was $0.01 \mathrm{~mol} \mathrm{dm}^{-3}$.

\section{Results and Discussion}

In the present paper, any chemical species in the organic phase is denoted by the subscript "org", while that in the aqueous phase is denoted by the lack of any subscript. The initial concentration is denoted by the subscript "init". The volume of the two liquid phases is assumed to be the same. The extraction equilibrium of $\mathrm{tba}^{+}$as ion-pairs with thiocyanate ions and also with nitrate ions can be written as:

$$
\begin{aligned}
& \mathrm{tba}^{+}+\mathrm{SCN}^{-} \rightleftharpoons \mathrm{tba}^{+} \mathrm{SCN}^{-}(\text {org }), \\
& K_{\mathrm{ex}_{\mathrm{A}, \mathrm{B}}}=\left[\mathrm{tba}^{+} \mathrm{SCN}^{-}\right]_{\mathrm{org}} /\left(\left[\mathrm{tba}^{+}\right]\left[\mathrm{SCN}^{-}\right]\right), \\
& \mathrm{tba}^{+}+\mathrm{NO}_{3}{ }^{-} \rightleftharpoons \mathrm{tba}^{+} \mathrm{NO}_{3}^{-}{ }_{(\mathrm{org})}, \\
& K_{\mathrm{ex}_{\mathrm{X}, \mathrm{B}}}=\left[\mathrm{tba}^{+} \mathrm{NO}_{3}^{-}\right]_{\mathrm{org}} /\left(\left[\mathrm{tba}^{+}\right]\left[\mathrm{NO}_{3}^{-}\right]\right)
\end{aligned}
$$

The values of these equilibrium constants were reported in a previous paper ${ }^{9}$ to be $K_{\mathrm{ex}_{\mathrm{A}, \mathrm{B}}}=10^{2.2}$ and $K_{\mathrm{ex}_{\mathrm{X}, \mathrm{B}}}=$ 
$10^{1.08}$. When no formation of ion-pairs in the aqueous phase is assumed, the initial concentration of $\mathrm{tba}^{+}$can be written as:

$$
\begin{aligned}
{\left[\mathrm{tba}^{+}\right]_{\text {init }}=} & {\left[\mathrm{tba}^{+}\right]+\left[\mathrm{tba}^{+} \mathrm{SCN}^{-}\right]_{\text {org }}+\left[\mathrm{tba}^{+} \mathrm{NO}_{3}{ }^{-}\right]_{\text {org }} } \\
& +\sum a\left[\left(\mathrm{tba}^{+}\right)_{a} \mathrm{Fe}^{\mathrm{III}}(\mathrm{SCN})_{a+3^{-}}\right]_{\text {org }} \\
& +\sum b\left[\left(\mathrm{tba}^{+}\right)_{b} \mathrm{Fe}^{\mathrm{II}}(\mathrm{SCN})_{b+2^{-b}}\right]_{\text {org. }} .
\end{aligned}
$$

However, since the initial tba ${ }^{+}$concentration is always much higher than the total concentration of iron complexes in the organic phase, the terms of the extracted iron(II) and iron(III) complexes in Eq.(3) should be negligible. Thus, Eq.(3) can be rewritten as:

$\left[\mathrm{tba}^{+}\right]_{\text {init }}=\left[\mathrm{tba}^{+}\right]+\left[\mathrm{tba}^{+} \mathrm{SCN}^{-}\right]_{\text {org }}+\left[\mathrm{tba}^{+} \mathrm{NO}_{3}{ }^{-}\right]_{\mathrm{org}}$ $\left[\mathrm{tba}^{+}\right]=\left[\mathrm{tba}^{+}\right]_{\text {init }} /\left(1+K_{\mathrm{ex}_{\mathrm{A}, \mathrm{B}}}\left[\mathrm{SCN}^{-}\right]+K_{\mathrm{ex}_{\mathrm{X}, \mathrm{B}}}\left[\mathrm{NO}_{3}^{-}\right]\right)$.

In such systems, the extraction of these ion-pairs also decreases the concentration of thiocyanate ions in the aqueous phase, but decreases the concentration of nitrate ions only slightly. Thus, the following equations can be written:

$$
\begin{aligned}
& {\left[\mathrm{SCN}^{-}\right]_{\text {init }}=\left[\mathrm{SCN}^{-}\right]+\left[\mathrm{tba}^{+} \mathrm{SCN}^{-}\right]_{\text {org }}} \\
& {\left[\mathrm{SCN}^{-}\right]=\left[\mathrm{SCN}^{-}\right]_{\text {init }} /\left(1+K_{\mathrm{ex}_{\mathrm{A}, \mathrm{B}}}\left[\mathrm{tba}^{+}\right]\right) .}
\end{aligned}
$$

By using Eqs.(4) and (5), the tba ${ }^{+}$and $\mathrm{SCN}^{-}$concentrations in the aqueous phase which are available for the formation and extraction of iron complexes can be calculated.

The distribution ratio of iron(III) can be written as:

$$
\begin{aligned}
D_{\mathrm{III}}= & \sum\left[\left(\mathrm{tba}^{+}\right)_{a} \mathrm{Fe}^{\mathrm{IIII}}(\mathrm{SCN})_{a+3}{ }^{-a}\right]_{\mathrm{org}} / \\
& \left(\left[\mathrm{Fe}^{3+}\right]+\sum\left[\mathrm{Fe}^{\mathrm{III}}(\mathrm{SCN})_{m}^{3-m}\right]\right) \\
= & \sum\left(K_{\mathrm{ex}_{a+3, a}}\left[\mathrm{tba}^{+}\right]^{a}\left[\mathrm{SCN}^{-}\right]^{a+3}\right) /\left(1+\sum \beta_{m}\left[\mathrm{SCN}^{-}\right]^{m}\right)
\end{aligned}
$$

where $\beta_{m}=\left[\mathrm{Fe}^{\mathrm{III}}(\mathrm{SCN})_{m^{3-m}}\right]\left[\mathrm{Fe}^{3+}\right]^{-1}\left[\mathrm{SCN}^{-}\right]^{-m}$

$$
\begin{aligned}
K_{\mathrm{ex}_{a+3, a}=}= & {\left[\left(\mathrm{tba}^{+}\right)_{a} \mathrm{Fe}^{\mathrm{III}}(\mathrm{SCN})_{a+3}{ }^{-a}\right]_{\operatorname{org}} \times } \\
& {\left[\mathrm{tba}^{+}\right]^{-a}\left[\mathrm{Fe}^{3+}\right]^{-1}\left[\mathrm{SCN}^{-}\right]^{-(a+3)} . }
\end{aligned}
$$

The distribution ratio of iron(II) can be written as:

$$
\begin{aligned}
D_{\mathrm{II}}= & \sum\left[\left(\mathrm{tba}^{+}\right)_{b} \mathrm{Fe}^{\mathrm{II}}(\mathrm{SCN})_{b+2^{-b}}\right]_{\text {org }} / \\
& \left(\left[\mathrm{Fe}^{2+}\right]+\sum\left[\mathrm{Fe}^{\mathrm{II}}(\mathrm{SCN})_{n}^{2-n}\right]\right) \\
= & \sum\left(K_{\mathrm{ex}_{b+2, b}}\left[\mathrm{tba}^{+}\right]^{b}\left[\mathrm{SCN}^{-}\right]^{b+2}\right) /\left(1+\sum \beta_{n}\left[\mathrm{SCN}^{-}\right]^{n}\right)
\end{aligned}
$$

where $\beta_{n}=\left[\mathrm{Fe}^{\mathrm{II}}(\mathrm{SCN})_{n}{ }^{2-n}\right]\left[\mathrm{Fe}^{2+}\right]^{-1}\left[\mathrm{SCN}^{-}\right]^{-n}$

$$
\begin{array}{r}
K_{\mathrm{ex}_{b+2, b}=}=\left[\left(\mathrm{tba}^{+}\right)_{b} \mathrm{Fe}^{\mathrm{II}}(\mathrm{SCN})_{b+2}{ }^{-b}\right]_{\text {org }} \times \\
{\left[\mathrm{tba}^{+}\right]^{-b}\left[\mathrm{Fe}^{2+}\right]^{-1}\left[\mathrm{SCN}^{-}\right]^{-(b+2)} .}
\end{array}
$$

The distribution ratio of iron(III) when extracted from $1 \mathrm{~mol} \mathrm{dm}{ }^{-3} \mathrm{Na}\left(\mathrm{SCN}, \mathrm{NO}_{3}\right)$ into chloroform did not change during the two-phase agitation for $30 \mathrm{~s}$ to 3 min. Thus, it was concluded that the change in the oxidation state of iron and in the chemical form of the

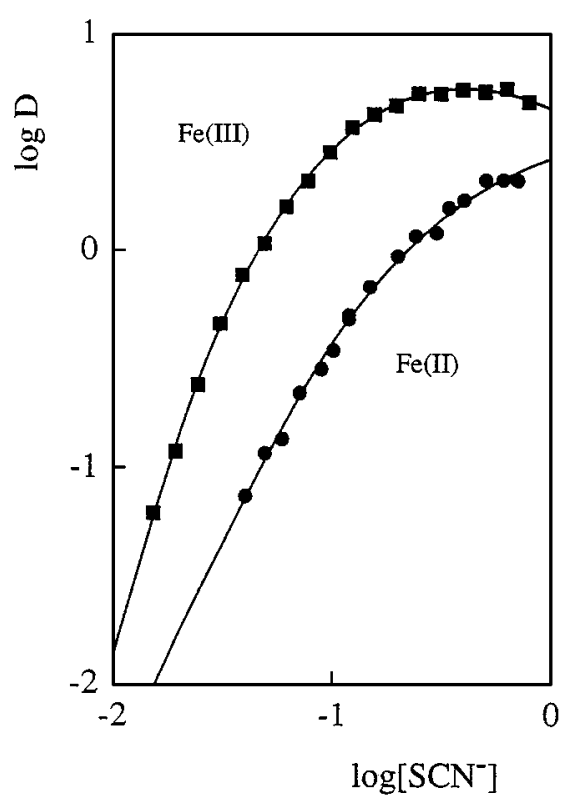

Fig. 1 Solvent extraction of iron(II) and (III) in $1 \mathrm{~mol} \mathrm{dm}^{-3}$ $\mathrm{Na}\left(\mathrm{SCN}, \mathrm{NO}_{3}\right)$ into chloroform with $4 \times 10^{-3} \mathrm{~mol} \mathrm{dm}^{-3} \mathrm{tba}^{+}$ (initial value in the aqueous phase). In the iron(II) extraction system, $0.01 \mathrm{~mol} \mathrm{dm}^{-3}$ ascorbic acid is added into the aqueous phase.

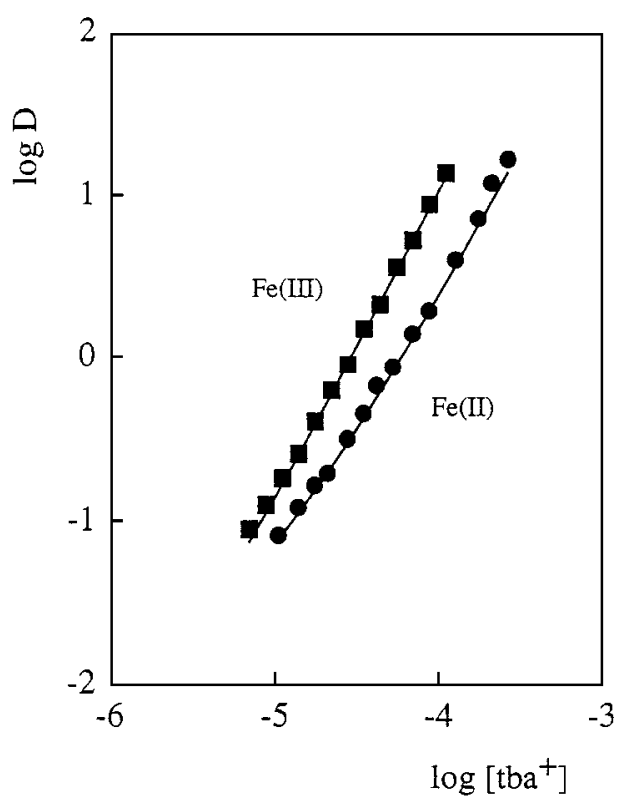

Fig. 2 Dependence of iron extraction on the calculated tba ${ }^{+}$ concentration at equilibrium in the aqueous phase. Aq. phase: $1 \mathrm{~mol} \mathrm{dm}^{-3} \mathrm{Na}\left(\mathrm{SCN}, \mathrm{NO}_{3}\right)$ initially containing $0.3 \mathrm{~mol} \mathrm{dm}^{-3}$ $\mathrm{SCN}^{-}$and $4 \times 10^{-4}$ to $6 \times 10^{-3} \mathrm{~mol} \mathrm{dm}^{-3}$ tba $^{+} \mathrm{NO}_{3}^{-}$; org. phase: chloroform. In the iron(II) extraction system, $0.01 \mathrm{~mol} \mathrm{dm}^{-3}$ ascorbic acid is added into the aqueous phase.

complexes in the both phases should be negligible during two-phase agitation for at least $3 \mathrm{~min}$. Figure 1 gives the extraction data of iron(III) as a function of the thiocyanate concentration, and Fig. 2 gives those as a function of the tba ${ }^{+}$concentration in the aqueous phase 
at equilibrium, which was calculated on the basis of Eq.(4). It was found during the experiments that the iron(III) thiocyanate complexes in the two phases had absorption in the visible region.

Experiments with iron(II) were carried out in the presence of $0.01 \mathrm{~mol} \mathrm{dm}^{-3}$ ascorbic acid in $1 \mathrm{~mol} \mathrm{dm}^{-3}$ $\mathrm{Na}\left(\mathrm{SCN}, \mathrm{NO}_{3}\right)$ solutions. When a portion of iron(III) stock solution was added to these aqueous solutions, the absorption in the range of 450 to $500 \mathrm{~nm}$, due to the iron(III) thiocyanate complexes, was negligible. Thus, it was concluded that the reduction of iron(III) to iron(II) by ascorbic acid was rapid and quantitative under these conditions. It was also found that the distribution ratio of iron reached a certain value by twophase agitation for $30 \mathrm{~s}$, and did not change for at least 3 min. Furthermore, the absorption of the two liquid phases in the visible region was negligible during agitation for such a short time. Thus, it was also concluded that the oxidation of $\mathrm{Fe}^{2+}$ and iron(II) thiocyanate complexes during solvent extraction experiments was negligible when the two phases were agitated for $30 \mathrm{~s}$ to 3 min. Figure 1 also gives the extraction data of iron(II) as a function of the thiocyanate concentration, and Fig. 2 also gives those as a function of the $\mathrm{tba}^{+}$concentration in the aqueous phase.

The solvent extraction data in Figs. 1 and 2 were statistically analyzed on the basis of Eq.(7) for iron(III) and on the basis of Eq.(11) for iron(II) by a successive approximation method using a least-squares computer program. It was found that the extraction data of iron(III) could be well explained by assuming the extraction of $\mathrm{tba}^{+} \mathrm{Fe}^{\mathrm{III}}(\mathrm{SCN})_{4}{ }^{-}$and $\left(\mathrm{tba}^{+}\right)_{2} \mathrm{Fe}^{\mathrm{III}}(\mathrm{SCN})_{5}{ }^{2-}$ into the organic phase and the formation of $\mathrm{Fe}^{\mathrm{III}}(\mathrm{SCN})^{2+}, \mathrm{Fe}^{\mathrm{III}}(\mathrm{SCN})_{2}{ }^{+}, \mathrm{Fe}^{\mathrm{III}}(\mathrm{SCN})_{3}$ and $\mathrm{Fe}^{\mathrm{III}}(\mathrm{SCN})_{4}$ in the aqueous phase while those of iron(II) could be well explained by assuming the extraction of tba ${ }^{+} \mathrm{Fe}^{\mathrm{II}}(\mathrm{SCN})_{3}{ }^{-}$and $\left(\mathrm{tba}^{+}\right)_{2} \mathrm{Fe}^{\mathrm{II}}(\mathrm{SCN})_{4}{ }^{2-}$ into the organic phase and the formation of $\mathrm{Fe}^{\mathrm{II}}(\mathrm{SCN})^{+}$and $\mathrm{Fe}^{\mathrm{II}}(\mathrm{SCN})_{2}$ in the aqueous phase. The stability and extraction constants for these obtained complexes are listed in Table 1. The solid curves in Figs. 1 and 2 are calculated by introducing these constants into Eq. (7) and into Eq. (11). Since the solid curves fit well with the experimental data, the values of constants should be reasonable.

From the stability constants of the iron thiocyanate complexes in the aqueous phase, the ratio of the com-

Table 1 Stability and extraction constants of iron(II) and (III) thiocyanate complexes

\begin{tabular}{lcccc}
\hline & $\log \beta_{1}$ & $\log \beta_{2}$ & $\log \beta_{3}$ & $\log \beta_{4}$ \\
$\mathrm{Fe}(\mathrm{II})$ & 2.8 & 3.4 & - & - \\
$\mathrm{Fe}(\mathrm{III})$ & 1.7 & 3.4 & 5.1 & 5.3 \\
& $\log K_{\mathrm{ex} 3,1}$ & $\log K_{\text {ex } 4,2}$ & $\log K_{\text {ex } 4,1}$ & $\log K_{\text {ex } 5,2}$ \\
& 7.9 & 13.0 & & \\
$\mathrm{Fe}(\mathrm{II})$ & & & 9.3 & 15.4 \\
$\mathrm{Fe}(\mathrm{III})$ & & & & \\
\hline
\end{tabular}

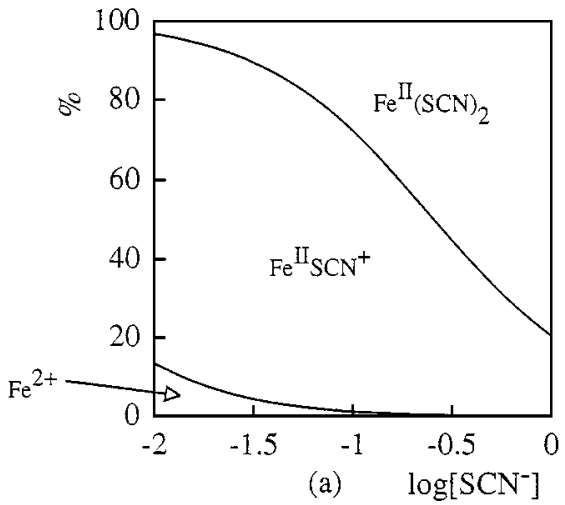

$\mathrm{Fe}(\mathrm{II})$

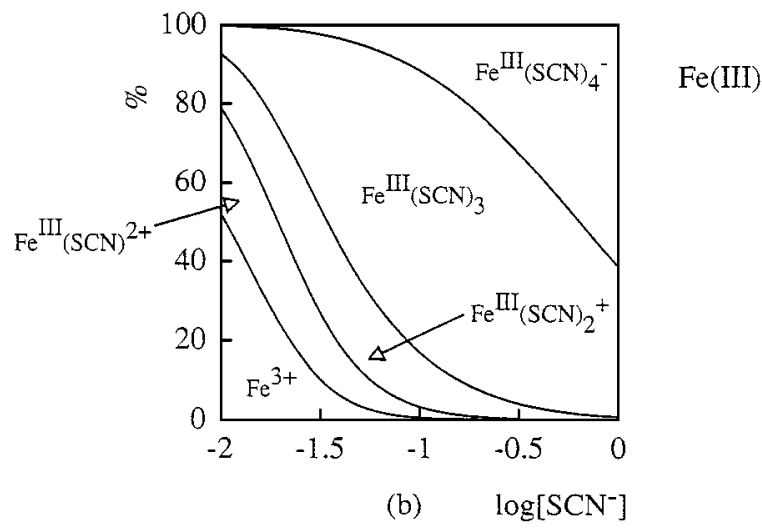

Fig. 3 Calculated molar ratio of iron(II) and (III) species in the aqueous phase as a function of the thiocyanate concentration on the basis of the stability constants of the complexes given in Table 1.

plexes was calculated as a function of the thiocyanate concentration. Figures 3(a) and 3(b) give the calculated percentage ratio of each complex. As can be seen from Fig. 3(a), the extracted two iron(II) complexes are statistically estimated to be negligible in the aqueous phase. It can also be seen from Fig. 3(b) that the extracted species, $\mathrm{Fe}^{\mathrm{III}}(\mathrm{SCN})_{5}{ }^{2-}$, is negligible and only $\mathrm{Fe}^{\mathrm{III}}(\mathrm{SCN})_{4}^{-}$is statistically estimated to be present in the aqueous phase.

Under the conditions where the concentration of thiocyanate is the same and that of $\mathrm{ba}^{+}$, the distribution ratio of iron(II) and (III) is not very much different, as can be seen from Figs. 1 and 2. When the thiocyanate concentration is higher, a larger amount of $\mathrm{tba}^{+}$should be extracted as ion-pairs with thiocyanate ions and this decreases the tba $^{+}$concentration in the aqueous phase. The extraction of metal complexes is affected not only by the complex formation, but also by the change in the tba $^{+}$concentration. The experimentally obtained results were affected by these two inverse effects.

\section{References}

1. L. G. Sillen and A. E. Martell, "Stability Constants", The Chemical Society, spec. pub., 17 (1964), 25 (1971).

2. E. B. Sandell, "Colorimetric Determination of Traces of 
Metals", pp. 524 - 537, Interscience Publishers Inc., New York, 1965.

3. T. Sekine and Y. Hasegawa, "Solvent Extraction Chemistry”, pp. 583 - 588, Marcel Decker, New York, 1977.

4. R. Cezary, Chem. Anal. [Warsaw], 14, 755 (1969).

5. H. Specker and E. Jackwerth, Naturwissenschaften, 46, 446 (1959).

6. E. Jackwerth, Z. Anal. Chem., 206, 335 (1964).
7. E. Jackwerth and E. L. Schneider, Z. Anal. Chem., 207, 188 (1965).

8. H. Matsuo, S. Chaki and S. Hara, Bunseki Kagaku, 15, 692 (1966).

9. Y. Ohmiya, N. T. K. Dung and T. Sekine, Bull. Chem. Soc. Jpn., 70, 1867 (1997).

(Received July 22, 1998)

(Accepted November 26, 1998) 